\title{
Sistema silvipastoril na Amazônia: ferramenta para elevar o desempenho produtivo de búfalos
}

\author{
Silvopastoral system in the Amazon region: tool to increase the productive \\ performance of buffaloes
}

\begin{abstract}
Anderson Corrêa Castro ${ }^{\mathrm{I}}$ José de Brito Lourenço Júnior ${ }^{\mathrm{II}}$ Núbia de Fátima Alves dos Santos ${ }^{\mathrm{I}}$ Edwana Mara Moreira Monteiro ${ }^{\mathrm{I}}$ Márcia Alessandra Brito de Aviz ${ }^{\mathrm{I}}$ Alexandre Rossetto Garcia ${ }^{\mathrm{II}}$
\end{abstract}

\section{- REVISÃO BIBLIOGRÁFICA -}

RESUMO

Os sistemas agroflorestais são arranjos de técnicas alternativas de uso de solo, combinando espécies florestais, culturas agrícolas e atividades pecuárias. Os sistemas silvipastoris são alternativas menos impactantes, auxiliam na reversão de áreas alteradas e contribuem para elevar a biodiversidade. Eles exploram eficientemente os recursos naturais, controlam o processo erosivo, melhoram a estrutura do solo e equilibram a atividade dos microorganismos, promovem a formação de pastagens de melhor qualidade, além de que proporcionam ambiência animal em função do sombreamento das pastagens. Também servem como barreira contra os ventos, diminuindo o estresse térmico e melhorando o desempenho animal. Esta revisão bibliográfica descreve o sistema silvipastoril como estratégia de manejo de búfalos, visando elevar seu desempenho produtivo.

Palavras-chave: ambiência, manejo, pastagem, bubalino.

\section{ABSTRACT}

Agroforestry systems are alternative techniques for the soil used, involving forest species, agricultural crops and livestock. Silvopastoral Systems are a less aggressive alternative, contributing to the reversion of altered areas and to raise biodiversity. These systems explore natural resources, controlled erosive process, improve the soil structure and balance the microorganisms activity, promote better quality of the pastures, providing animal ambience, due to the efficient shade of pastures. Thus, provide barrier against the winds, decreasing thermal stress and improving animal performance. This review describes the silvopastoral system as a strategy for management of buffaloes, aiming to raise productive performance.

Key words: ambience, management, pasture, buffalo.

\section{INTRODUÇÃO}

A criação de ruminantes nos trópicos contribui para a produção de alimentos de elevado valor biológico, como carne e leite (MARQUES \& CARDOSO, 1997). A região tropical apresenta elevados índices de precipitação pluviométrica, temperatura, umidade relativa do ar e radiação solar. Estas, quando associadas ao manejo inadequado da pastagem e do animal, podem ser consideradas elementos estressantes e que prejudicam a exteriorização do potencial produtivo dos bovídeos (NASCIMENTO \& MOURA CARVALHO, 1993; SHALASH, 1994; PARANHOS DA COSTA, 2000).

A adoção de sistemas agroflorestais sistemas agrosilvipastoris e silvipastoris - com cultivos anuais, essências florestais, pastagem e animais (VEIGA \& SERRÃO, 1990; PEZO \& IBRAHIM, 1998; LOURENÇO JÚNIOR et al., 2002) reduz os efeitos negativos dos rigores impostos pelo clima tropical aos

'Programa de Pós-graduação em Ciências Agrárias/Agroecossistemas da Amazônia, Universidade Federal Rural da Amazônia (UFRA), Belém, PA, Brasil.

IIPrograma de Pós-graduação em Ciências Agrárias/Agroecossistemas da Amazônia e Programa de Pós-graduação em Ciência Animal, Universidade Federal do Pará (UFPA), Belém, PA, Brasil. E-mail: lourenco@amazon.com.br. Autor para correspondência.

IIIEmbrapa Amazônia Oriental. Belém, PA, Brasil. 
animais e melhora a utilização dos recursos naturais, com conseqüente aumento na produtividade e redução de custos (CARVALHO, 1998; FALESI \& GALEÃO, 2002), Assim, seu uso torna a agropecuária uma atividade intensiva e sustentável, com rentabilidade, pela comercialização de produtos e derivados, agregando valor à propriedade, além do paisagismo, que permite o ecoturismo (PEZO \& IBRAHIM, 1998).

O búfalo tem espaço garantido como opção pecuária. No que se refere aos produtos (carne, leite e derivados), não restam dúvidas sobre a excelente qualidade, as características sensoriais, as propriedades nutricionais e funcionais. Além disso, o búfalo tem adaptabilidade, rusticidade para transformar gramíneas em derivados de alto valor agregado e como componente em sistemas agrosilvipastoris. Quando praticada em pequenas propriedades, a bubalinocultura gera ganhos substanciais às famílias agrícolas e, por isso, tem-se mostrado relevante instrumento de progresso social (CASTRO, 2005; BERNARDES, 2007).

$\mathrm{Na}$ Amazônia, as pesquisas sobre ecofisiologia de bubalinos que envolvam o manejo do ambiente físico para elevação do conforto e, como conseqüência, a produtividade desses animais, são escassas (MAGALHÃES et al., 1998). O objetivo desta revisão bibliográfica é apresentar a importância do sistema silvipastoril como estratégia de manejo ambiental para o incremento da ambiência de búfalos, visando elevar seu desempenho produtivo.

\section{Panorama amazônico}

AAmazônia possui a maior floresta tropical do mundo, com cerca de 5,5 milhões de $\mathrm{km}^{2}$, sendo o maior reservatório de diversidade biológica do planeta. Até meados da década de 60, a sua exploração era de forma extrativista, sem significativos impactos ambientais. Entretanto, posteriormente, a exploração se intensificou, para integrar a região ao processo produtivo e econômico do país. A pecuária, uma das atividades econômicas que mais se desenvolveram na ocupação e na utilização das terras, contribuiu para que grandes extensões de florestas fossem desmatadas e cedessem lugar às pastagens cultivas (FALESI, 1992; COSTA et al., 2000).

Nas zonas de franco desenvolvimento pecuário, no Sul, Sudeste e Oeste do Pará, Norte de Tocantins e Mato Grosso, pré-Amazônia maranhense, Rondônia, Amazonas e Acre, a floresta foi substituída por pastagens cultivadas. O manejo inadequado da forrageira e do animal, além do uso de espécies de gramíneas não-adaptadas às condições edafoclimáticas locais, reduziram a disponibilidade e o valor nutritivo das pastagens, alcançando estádio de degradação e conseqüente invasão de plantas indesejáveis. Os efeitos foram prejudiciais ao ambiente físico, com efeitos negativos e até irreversíveis aos ecossistemas locais (LOURENÇO JÚNIOR, 1998; DUTRA et al., 2000; COSTA et al., 2000). Além disso, a superlotação das pastagens e a ausência de adubação são importantes causas de degradação de pastagens na Amazônia Legal e em outros locais do país (DIAS FILHO, 2005). Por outro lado, o uso do fogo como instrumento de "limpeza" (controle de invasoras) ou de eliminação do excesso de pasto não-consumido, constitui fator acelerador da degradação de pastagens cultivadas, principalmente para pequenos produtores (DIAS FILHO \& ANDRADE, 2005).

Na formação de pastagens de "melhor qualidade” e expansão da fronteira agrícola, anualmente, são registrados desmatamentos para atividades econômicas, como extração de madeira e produção agropecuária. Até 1996, 24 milhões de hectares de floresta da Amazônia foram transformados em pastagens, principalmente, no Pará. A área total desmatada na Amazônia brasileira, considerando-se as pastagens cultivadas e as ocupadas com produção agrícola, ultrapassa 50 milhões de ha (COSTA et al., 2000; FALESI \& GALEÃO, 2002).

Nos trópicos úmidos, o ganho inicial da fertilidade dos solos se deve ao corte e à queima da vegetação, com incorporação de grande quantidade de matéria orgânica, originalmente componente da parte aérea dos vegetais. No entanto, essa fertilidade é rapidamente reduzida, quando a vegetação original não é substituída por sistemas de uso da terra, capazes de proteger o solo e reciclar nutrientes (BROWDER, 1988; HECHT et al., 1988). O principal problema das pastagens na Amazônia é a sua degradação. Esse fato se deve, principalmente, à pressão de pastejo muito superior a sua capacidade de suporte, reduzindo sua vida útil. Outros fatores estão relacionados à fertilidade do solo, que são pobres e ligeiramente ácidos, além de pragas, doenças e invasão de plantas indesejáveis (VEIGA et al., 1996).

De acordo com estimativas, 45, 28 e $2 \%$ da área total desmatada na Amazônia representavam, respectivamente, pastagens produtivas, áreas de capoeira (resultantes de pastagens abandonadas depois de 1970), e pastagens degradadas. Por essa razão, a formação de pastagens na região tem sido o centro de duras críticas por parte de ambientalistas (FEARNSIDE \& BARBOSA, 1998). Os impactos ambientais e socioeconômicos, causados pela substituição de extensas áreas de florestas por pastagens, têm sido objeto de constante preocupação 
por parte da comunidade mundial. Por isso, o fomento às atividades econômicas sustentáveis e a geração de soluções tecnológicas que viabilizem a produção pecuária em áreas já alteradas da Amazônia, priorizando sistemas ambientalmente recomendáveis, socialmente justos e economicamente rentáveis, são de fundamental importância. Nesse contexto, a utilização de sistemas silvipastoris pode representar uma alternativa atraente para maximizar o uso da terra, com sustentabilidade.

\section{Sistemas silvipastoris (SSP's)}

Em função da crescente conscientização sobre a importância da preservação ambiental e da criação de leis que disciplinem a ação humana sobre a floresta, aumenta o interesse em programas que visem à revegetação de áreas degradadas, o que implica geração de conhecimentos técnico-científicos, em centros de pesquisas a fim de reduzir ou amenizar problemas de ordem ecológica. Na tentativa de reverter a degradação ambiental dos ecossistemas amazônicos, várias pesquisas foram desenvolvidas com o intuito de promover o desenvolvimento sustentável da região, com custos sociais, econômicos e ambientais mínimos (SERRÃO \& HOMMA, 1991; FALESI \& GALEÃO, 2002). Para suavizar a pressão de desmatamento, é de fundamental importância a intensificação do uso do solo de áreas desmatadas, como vem ocorrendo no Nordeste paraense. Deve-se salientar que a floresta se recupera à base de $1 \mathrm{~m}^{3} \mathrm{ha}^{-1} \mathrm{ano}^{-1}$, enquanto o reflorestamento assegura, no mínimo, $10 \mathrm{~m}^{3} \mathrm{ha}^{-1} \mathrm{ano}^{-1}$, significando que cada hectare reflorestado garante a proteção de 10 hectares de mata (FALESI \& GALEÃO, 2002; TEREZO, 2002).

Entre os tipos existentes de sistemas agroflorestais (SAF's), os sistemas silvipastoris (SSP's) constituem forma alternativa de uso da terra e exploração agrícola, sendo baseados no consórcio de cultivos arbóreos, pastagens e animais, de forma simultânea ou seqüencial. Apresentam maior sustentabilidade biológica, econômica, social e ecológica, quando comparados com sistemas produtivos tradicionais, como o monocultivo de pastagens (PAYNE, 1985; MONTAGNINI, 1992). Os SSP's têm como objetivo principal aumentar a eficiência de uso dos recursos naturais e diversificar a produção da propriedade, envolvendo várias atividades agrícolas. Assim, em regiões tropicais úmidas, a integração entre rebanhos e cultivos arbóreos pode reproduzir os benefícios ecológicos da floresta e reduzir os impactos ambientais decorrentes do desmatamento para formar pastagens (PAYNE, 1985).
Nas regiões tropicais, após o desmatamento de uma área para estabelecimento de pastagens ou cultivo agrícola, quebra-se o equilíbrio do ecossistema sustentável. Para ser estável, o agroecossistema deve restabelecer os mecanismos do equilíbrio anterior, como a reciclagem de nutrientes e a conservação das características físico-químicas dos solos. Têm sido comprovados os benefícios dos SSP, os quais proporcionam a conservação dos solos tropicais (VEIGA et al., 1996). As copas das árvores contribuem para a redução do processo erosivo do solo, por reduzirem o impacto das chuvas. Por outro lado, o seu sistema radicular, que geralmente é denso e profundo, forma barreiras, impedindo o arraste das partículas do solo, bem como pode absorver os nutrientes das camadas mais profundas, translocando-os para as folhas. Após sua queda, deposição e decomposição, tornam-se excelentes fontes de adubação orgânica, melhorando as características físicas e químicas do solo (MONTAGNINI, 1992; CARVALHO, 1998; PEZO \& IBRAHIM, 1998).

Existem outras vantagens proporcionadas pelas árvores nos ecossistemas pecuários, como o microclima, que beneficia as plantas e os animais. As copas das árvores funcionam, também, como quebraventos, diminuindo a demanda evaporativa das plantas herbáceas dos sub-bosques em relação às variações microclimáticas. Em períodos de estiagem, os solos apresentam maior teor de umidade sob a sua copa do que em áreas expostas diretamente ao sol e vento, contribuindo para melhorar o desempenho quantitativo e qualitativo das gramíneas forrageiras (ANDERSON et al., 1988; CARVALHO, 1998).

Pesquisa com búfalos criados em sistema silvipastoril e pastejo rotacionado intensivo durante 18 meses, em Belém, Pará (CASTRO, 2005), mensurou a disponibilidade de forragem (Cynodon nlemfuensis) nos períodos mais e menos chuvosos. No período chuvoso (dezembro a maio), observou-se maior disponibilidade de forragem, com produção de $3.318,9 \mathrm{~kg}$ de MS ha-1, enquanto no menos chuvoso (junho a novembro) houve redução para 2.504,3kg de MS ha-1. Essas disponibilidades estão acima da necessidade mínima exigida pelos bubalinos para bom desempenho produtivo que é de 1.200 a $1.600 \mathrm{~kg}_{\text {de }} \mathrm{MS} \mathrm{ha}^{-1}$ (MOTT, 1980), corroboradas pelo desempenho ponderal dos animais, que atingiram média $0,911 \mathrm{~kg} \mathrm{dia}^{-1}$, superior aos observados no setor produtivo da Amazônia, o que evidencia que o sistema silvipastoril proporciona excelente opção para elevar a performance dos sistemas de produção. TOWNSEND et al. (2000), avaliando o desempenho de novilhos bubalinos em diferentes sistemas silvipastoris (pastagem sob sombreamento 
de seringal, pastagem com bosque de espécies florestais nativas e pastagem a pleno sol), observaram que animais mantidos sob sombra ganharam mais peso que os mantidos em pastagens a pleno sol (757, 472 e $337 \mathrm{~g}$ animal ${ }^{-1} \mathrm{dia}^{-1}$, respectivamente), o que demonstra os efeitos benéficos da sombra.

Maiores valores de digestibilidade in vitro da matéria orgânica (DIVMO) do caule, da folha e da planta inteira da grama estrela ocorreram no período mais chuvoso, respectivamente, 44,54, 44,61 e 42,91\%, devido à maior disponibilidade de massa verde. Por outro lado, no período menos chuvoso, a DIVMO foi reduzida para 41,87 e $42,56 \%$, principalmente, no caule e na folha, enquanto que na planta inteira não sofreu oscilações nos dois períodos do ano, com valores em torno de 41\% (CASTRO, 2005).

Os fatores climáticos dos trópicos úmidos, a elevada temperatura do ar e a radiação solar afetam diretamente a termorregulação e o comportamento animal, o consumo de forragem e a utilização de água, prejudicando o crescimento, o desempenho produtivo e reprodutivo animal. Em pastagens, com reduzido número de árvores, os bovídeos sofrem nas horas mais quentes, principalmente os bubalinos, devido à quantidade reduzida de glândulas sudoríparas que os mesmos possuem, e os bovinos de raças européias (BERBIGIER, 1988; BAUMER, 1991; MAGALHÃES et al., 1998). Assim, os SSP's são importantes para a ambiência animal, pois reduzem a insolação e a temperatura ambiente, promovendo melhor desempenho produtivo, devido às condições ideais de aclimatação (VEIGA \& SERRÃO, 1990; PEZO \& IBRAHIM, 1998; LOURENÇO JÚNIOR et al., 2002). A fim de reduzir os efeitos negativos do clima sobre os animais o sombreamento das pastagens proporcionado pelo uso dos SSP's torna-se um elemento favorável para a criação de búfalos, principalmente nas regiões tropicais e em função da disponibilidade cada vez mais restrita de fontes naturais de água para banho.

Na Embrapa Rondônia foi avaliada a influência de sistemas silvipastoris sobre o ambiente e os animais. Os animais foram criados em sistema sombreado (pastagem de Brachiaria brizantha cv. "Marandu” sob seringal adulto - Hevea brasiliensis), parcialmente sombreado (pastagem de Brachiaria brizantha cv. "Marandu", associada a bosque de espécies florestais nativas, cobrindo cerca de $10 \%$ da área do pasto) e a pleno sol (pastagem de Brachiaria brizantha cv. "Marandu”). As temperaturas médias registradas nos termômetros de globo negro na pastagem sob seringal foram inferiores $(\mathrm{P}<0,05)$ às registradas nas pastagens parcialmente sombreada e a pleno sol, tanto na estação chuvosa como na seca, sendo que o diferencial térmico entre esses sistemas foi de $4,30^{\circ} \mathrm{C}$ (TOWNSEND et al., 2000). Assim, animais protegidos do calor pastam por períodos mais longos, o que reduz, em média, 20\% o consumo de água e proporciona melhor conversão alimentar, elevando a produção de carne e leite.

A temperatura do ar, sob a copa das árvores, pode ser de $2^{\circ} \mathrm{C}$ a $3^{\circ} \mathrm{C}$ inferior à observada a pleno sol, podendo reduzir até $9,5^{\circ} \mathrm{C}$ (BAUMER, 1991; PEZO \& IBRAHIM, 1998). Além disso, as árvores interferem na passagem da radiação solar, reduzindo o incremento calórico dos animais em pastejo. Pesquisas têm demonstrado que búfalos criados em pastagem sem sombreamento apresentam elevação significativa na temperatura retal $\left(\right.$ de $38,3^{\circ} \mathrm{C}$ para $39,1^{\circ} \mathrm{C}$ ), na freqüência respiratória (de 22,6mov $\mathrm{min}^{-1}$ para 48,4mov $\mathrm{min}^{-1}$ ) e na taxa de sudorese (de 107,3g m $\mathrm{g} \mathrm{h}^{-1}$ para $252,2 \mathrm{~g} \mathrm{~m}^{-2} \mathrm{~h}^{-1}$ ), como forma de dissipar o excesso de calor corporal, em decorrência do estresse térmico, prejudicando seu desempenho produtivo (PARANHOS DA COSTA, 2000). Em trabalho realizado por LOURENÇO JÚNIOR et al. (2006), foi observado que as essências florestais (mogno africano e nim indiano) no sistema silvipastoril possibilitam sombreamento suficiente para promover maior ambiência e elevar o desempenho produtivo de búfalas leiteiras. Nesse trabalho, foi avaliado o índice de conforto de Benezra (ICB), que considera a temperatura retal e a freqüência respiratória, sendo que valores próximos a dois $(2,0)$ representam animais com alto grau de adaptabilidade ao meio ambiente. Foi observado que o ICB dos animais mantidos no sistema com sombra é mais próximo a 2,0 em $70 \%$ das observações realizadas, o que comprova a importância da sombra na ambiência animal, em climas tropicais, como o da Amazônia brasileira.

No trabalho de CASTRO (2005), foi mensurada a temperatura retal para verificar a influência do ambiente sobre o conforto térmico de bubalinos. Todos os valores observados encontraram-se dentro da faixa de variação normal para bubalinos, conforme TITTO et al. (1997), sendo que a temperatura retal média encontrada foi de $38,7^{\circ} \mathrm{C}( \pm 0,39)$, com menores valores observados entre dezembro e janeiro, meses de maior pluviosidade. Houve, então, associações importantes entre a temperatura retal e a precipitação pluviométrica $(r=-0,61)$ e a temperatura máxima $(r=0,77)$. Chuvas intensas seguidas de períodos de veranicos contribuíram para o desconforto animal, elevando a temperatura retal para $38,9^{\circ} \mathrm{C}$. No entanto, à medida que as chuvas foram se intensificando, houve redução da temperatura do ar e maior nebulosidade, o que diminuiu a incidência de raios solares, favoreceu a dissipação de calor corpóreo e diminuiu a temperatura 
retal dos animais. Em trabalho com búfalas criadas em sistema silvipastoril e inseminadas em tempo fixo, MATOS et al. (2007) observaram que as maiores taxas de concepção ocorreram quando os animais apresentaram ICBs entre 1,9 e 2,1. A taxa de concepção dos animais com ICB entre 1,9 e 2,0 durante a sincronização do estro foi de 63,64\% (n=14/22), enquanto a taxa de concepção de todo lote foi de 48,21\% ( $n=27 / 56)$, demostrando que o ambiente de conforto térmico proporcionou melhores condições para a fertilização. Segundo DANTAS (2001), a concepção de búfalas em condições de clima quente e úmido está associada às variáveis climáticas, sendo estas responsáveis pelas variações fisiológicas dos animais e cujos impactos são minimizados com uso dos SSP's.

\section{Utilização de árvores em SSP's}

Uma das regras para suavizar a pressão de desmatamento é diversificar o uso do solo, por meio dos SSP's, observando-se aspectos de interação entre as espécies de valor econômico e com crescimento rápido, o que abrevia o retorno financeiro do sistema e estimula a adoção de técnicas sustentáveis e rentáveis (FALESI \& GALEÃO, 2002). Para o desenvolvimento de SSP's na Amazônia, tem sido utilizadas plantas arbóreas como o inajá (Maximiana maripa), o babaçu (Orbignia phalerata), о coco (Cocus nucifera), o dendê (Elaeis guineensis), além da utilização de essências florestais nativas, como o paricá (Eschyzolobium amazonicum), o mogno amazônico (Swietenia macrophila), a castanhado-pará (Bertolletia excelsa), o ipê (Tabebuia serratifolia), entre outras (VEIGA \& PEREIRA, 1998).

No estabelecimento de SSP's, as espécies exóticas vem ganhando destaque nos últimos anos para aumentar a eficiência do sistema e promover a preservação de espécies nativas exploradas na região (TEREZO, 2002). Por exemplo, pela alta suscetibilidade do mogno brasileiro (Swietenia macrophylla King) ao microlepidóptero Hypsiphyla grandella Zeller e forma alternativa, vem sendo indicado pela Embrapa Amazônia Oriental o uso de mogno africano (Khaya ivorensis A. Chev.) em plantios comerciais. O interesse para a sua utilização se deve ao elevado valor econômico internacional, pela beleza e durabilidade da madeira, além do aspecto ambiental e, principalmente, por apresentar crescimento relativamente rápido. Em SSP's, essa espécie, aos sete anos de idade, pode alcançar altura de $12 \mathrm{~m}$, correspondente à primeira ramificação da copa e diâmetro a altura do peito (DAP) de 22cm. Conforme estudo realizado no município de Igarapé-Açú, Pará, utilizando mogno-africano no estabelecimento de SSP's, foi observado que a utilização de adubos químicos é reduzida, pois o sistema radicular das árvores alcança volume considerável de solo, promove maior absorção de nutrientes e contribui para o equilíbrio ambiental do sistema, ao translocar nutrientes das camadas mais profundas e reciclar para as mais superficiais do solo. Segundo estimativas, uma árvore de mogno-africano, ao atingir o ponto de corte, em torno de 15 a 20 anos, poderá alcançar o valor de cerca de US\$ 2.000,00, não existindo outro produto agrícola que a supere (FALESI \& BAENA, 1999; FALESI \& GALEÃO, 2002).

Outra árvore exótica que se destaca e vem sendo utilizada em SSP's no Estado do Pará é o nim indiano (Azadirachta indica A. Juss). É uma espécie de fuste geralmente reto, com diâmetro médio variando entre 25 e $30 \mathrm{~cm}$, aos oito anos de idade. A densidade de sua madeira varia entre 0,56 e $0,85 \mathrm{~g} \mathrm{~cm}^{-3}$, apresenta coloração avermelhada, de consistência dura e resistente ao ataque de cupins e ao apodrecimento. Seu cerne é rico em tanino e sais inorgânicos de cálcio, potássio e ferro. Quanto às exigências edafoclimáticas, se desenvolve em regiões com precipitação pluviométrica anual entre $400 \mathrm{~mm}$ e $800 \mathrm{~mm}$, tolera a estiagem prolongada e as temperaturas elevadas, desde que por curto período. Por ser adaptada ao clima árido, seu sistema radicular pode atingir até 15 metros de profundidade em busca de água e nutrientes, tornandoa, assim, ideal para o desenvolvimento de SAF's (NEVES \& NOGUEIRA, 1996). Em municípios do Estado do Pará, como Castanhal, Igarapé-Açú e Santo Antônio do Tauá, o nim está sendo cultivado em algumas propriedades agrícolas, apresentando bom comportamento vegetativo, em que a velocidade de crescimento das plantas é marcante, atingindo aos 12 meses de idade a média de 2,80m de altura, com floração iniciando aos dois anos de idade (FALESI et al., 2000). O nim é empregado em arborização urbana e produção de lenha e madeira. Por ser da família das Meliaceae, apresenta compostos químicos conhecidos como meliacinas e entre elas, o "azadiractin”, substância bastante utilizada nas indústrias farmacêuticas. Encontrado nos frutos, nas sementes, nas folhas, na casca do caule e nas raízes, é utilizado como ingrediente na preparação de vários produtos, tais como medicamentos antivirais e antimicrobianos, cosméticos, creme dental, loções e sabonetes. A fabricação de produtos destinados ao combate de pragas também utiliza o azadiractin. Nos insetos, ele tem efeito repelente, provocando repulsa alimentar em plantações que foram tratadas com essa substância e, por ser natural, não tem ação fitotóxica, é atóxica ao homem e não contamina o ambiente. Devido ao seu uso múltiplo, essa espécie é ideal para o desenvolvimento de SSP's (KOUL et al., 1990; NEVES \& NOGUEIRA, 1996). 
Importância das gramíneas no desenvolvimento de SSP's

Um dos requisitos para o sucesso de SSP's sustentáveis deve-se à seleção de espécies para compor esses sistemas. Em se tratando de plantas forrageiras, há necessidade de que sejam tolerantes ao sombreamento, pois as alterações microclimáticas influenciam na disponibilidade de água e na fertilidade do solo, interferindo no crescimento das plantas. Também é necessário selecionar espécies que detenham boa capacidade produtiva, adaptadas ao manejo e ambientadas às condições edafoclimáticas da região (CARVALHO, 1998; GARCIA\&ANDRADE, 2001).

As gramíneas do gênero Cynodon apresentam flexibilidade de uso por possuírem satisfatório potencial de produção, vigor de rebrota, valor nutritivo satisfatório, tolerância ao sombreamento, além de serem adaptadas às mais variadas condições de clima e solo. Assim, tornam-se importantes como espécies forrageiras a serem utilizadas em SSP's. Essas gramíneas são cosmopolitas, invasoras e de caráter colonizador, freqüentemente encontradas nas regiões tropicais e subtropicais, sendo originárias do continente africano (Quênia, Tanzânia, Uganda e África Ocidental). Foram introduzidas no continente americano pelos espanhóis juntamente com fardos de feno destinados à alimentação animal (PEIXOTO et al., 1993; ALVIM et al., 1996).

A grama-estrela foi introduzida em várias regiões do Brasil. Em 1976, foi utilizada na Amazônia para formação de pastagem, pelo Projeto de Melhoramento de Pastagem da Amazônia Legal (PROPASTO), com restrições devido à reduzida fertilidade dos solos e à falta de tradição de uso da adubação química. Nas últimas décadas, pecuaristas do Nordeste paraense estão usando-a em sistemas de pastejo rotacionado intensivo. No entanto, são escassos experimentos que demonstrem o potencial produtivo/qualitativo do gênero Cynodon, associado às condições edafoclimáticas da Amazônia, para ter informações sobre seu manejo, sua produção e seu valor nutritivo (ALVIM et al., 1996; VILELA \& ALVIM, 1996). Em estudo com a grama-estrela em sistema silvipastoril, na Amazônia, CASTRO (2005) demonstrou que essa gramínea possui elevado potencial produtivo, apresentando satisfatória disponibilidade e valor nutritivo, com níveis de proteína e energia adequados à nutrição de ruminantes.

Perspectivas da bubalinocultura na Amazônia A importância econômica na exploração de búfalos reside, também, nas vantagens proporcionadas quanto à fertilidade, longevidade, eficiência de conversão alimentar e aptidão para a produção de leite, carne e trabalho (NASCIMENTO \& MOURA CARVALHO, 1993). Em sistemas tradicionais de criação da Amazônia, sem uso de inovações tecnológicas, a baixa rentabilidade da bubalinocultura torna essa atividade pouco atrativa economicamente, com o prognóstico de que a médio e longo prazos somente permanecerão nela os que forem competentes para adaptação à nova realidade das mudanças econômicas. Esse fato tem induzido os pecuaristas a transferirem parte dos búfalos para áreas já formadas com pastagens cultivadas na terra firme, ou realizarem investimentos na recuperação de áreas alteradas, visando elevar a produtividade e torná-las competitivas (LOURENÇO JÚNIOR et al., 2002).

A pecuária em pastagens cultivadas da Amazônia tem sido estigmatizada como responsável pela baixa eficiência do uso da terra. A rentabilidade da pecuária depende da eficácia da exploração, do manejo racional das pastagens, do melhoramento genético do rebanho, da produção intensiva de carne e/ou leite e da elevada produtividade, com economicidade e preservação do ambiente (VEIGA et al., 1996). Nos últimos anos, uma alternativa que tem sido utilizada com sucesso é o sistema integrado de pastagens, utilizando o potencial produtivo das forrageiras da várzea, na época seca, e as pastagens cultivadas, na terra firme, dos gêneros Brachiaria (Brachiaria humidicola, Brachiaria brizantha). Esse sistema não tem provocado significativos danos ambientais por utilizar áreas menores e alteradas. As pesquisas demonstram bons resultados no desempenho produtivo e econômico na terminação de bubalinos, o que permite que os animais atinjam entre $400 \mathrm{e}$ $450 \mathrm{~kg}$ de peso vivo, com idade inferior a dois anos (LOURENÇO JÚNIOR \& GARCIA, 2006).

Em futuro muito próximo, os sistemas agrosilvipastoris, entre os quais se destacam os silvipastoris, poderão ser relevantes para a bubalinocultura, na utilização de áreas alteradas por uso inadequado, agregando valor à terra, via componente arbóreo, possibilitando melhor ciclagem de nutrientes e maior conforto animal e representando alternativas atraentes para maximizar o uso da terra, com sustentabilidade. A criação de búfalos para produção de carne e leite se enquadra perfeitamente nesse contexto, com produtividade e efeitos benéficos na socioeconomia (VEIGA \& SERRÃO, 1990; LOURENÇO JÚNIOR et al., 2002). 


\section{CONCLUSÕES}

O desempenho produtivo e o conforto térmico dos animais mantidos em sistema silvipastoril são superiores à média dos sistemas tradicionais por fornecer sombreamento e melhorar o conforto animal e favorecer a sustentabilidade da atividade pecuária nos aspectos produtivos, biológicos, econômicos, sociais e ecológicos.

\section{AGRADECIMENTOS}

Ao Programa de Pós-graduação em Ciência Animal da Universidade Federal do Pará-UFPA, à Coordenação de Aperfeiçoamento de Pessoal de Nível Superior (CAPES) e ao Conselho Nacional de Pesquisa e Desenvolvimento Tecnológico (CNPq), pelas bolsas concedidas. Ao Banco da Amazõnia S.A., pelo apoio financeiro, através do Projeto Basa-Pecuária.

\section{REFERÊNCIAS}

ANDERSON, G.W. et al. The integration of pasture, livestock and widely-space pine in South West Western Australia. Agroforestry Systems, Holanda, v.6, n.1 p.195-211, 1988.

ALVIM, J.M. et al. Efeito da freqüência de corte e do nível de nitrogênio sobre a produção e qualidade da matéria seca do "cost-cross". In: WORKSHOP SOBRE O POTENCIAL FORRAGEIRO DO GÊNERO CYNODON, 1996, Juiz de Fora, MG. Anais... Juiz de Fora: EMBRAPA - CNPGL, 1996. p.4555.

BAUMER, M. Animal production, agroforestry and similar techniques. Agroforestry Systems, Holanda, v.4, n.4, p.17998, 1991.

BERBIGIER, P. Bioclimatologie des ruminants domestiques en zone tropicale. Paris: INRA, 1988. 237p.

BERNARDES, O. Bubalinocultura no Brasil: situação e importância econômica. Revista Brasileira de Reprodução Animal, Belo Horizonte, v.31, n.3, p.293-298, 2007.

BROWDER, J.O. The social cost of rain forest destruction: A critique and economic analysis of the "Hamburger debate". Interciencia, Venezuela, v.13, n.3, p.115-120, 1988.

CARVALHO, M.M. Arborização de pastagens cultivadas. Juiz de Fora: EMBRAPA-CNPGL, 1998. 37p. (EMBRAPACNPGL. Documentos, 64)

CASTRO, A.C. Avaliação de sistema silvipastoril através do desempenho produtivo de búfalos manejados nas condições climáticas de Belém, Pará. 2005. $87 \mathrm{f}$. Dissertação (Mestrado em Ciência Animal) - Curso de Pósgraduação em Ciência Animal, Universidade Federal do Pará.

COSTA, N.A. et al. Controle de plantas invasoras em pastagens cultivadas. In: ___ et al. Pastagens cultivadas na Amazônia. Belém: Embrapa Amazônia Oriental, 2000. p.72-98.

DANTAS, J.A.S. Influência de variáveis climáticas na fertilidade de búfalas Murrah e Mediterrâneo na
Amazônia Oriental. 2001. Dissertação (Mestrado em Ciência Animal) - Curso de Pós-graduação em Ciência Animal, Universidade Federal do Pará.

DIAS FILHO, M.B. Degradação de pastagens: processos, causas e estratégias de recuperação. 2.ed. Belém: Embrapa Amazônia Oriental, 2005. 173p.

DIAS FILHO, M.B.; ANDRADE, C.M.S. Pastagens no ecossistema do trópico úmido. In: SIMPÓSIO SOBRE PASTAGENS NOS ECOSSISTEMAS BRASILEIROS: alternativas viáveis visando a sustentabilidade dos ecossistemas de produção de ruminantes nos diferentes ecossistemas, 2005 , Goiânia. Anais... Goiânia: SBZ, 2005. p.95-104

DUTRA, S. et al. Sistemas de manejo das pastagens cultivadas. In: COSTA, N.A. et al. Pastagens cultivadas na Amazônia. Belém: Embrapa Amazônia Oriental, 2000. p.36-50.

FALESI, I.C. Efeitos da queima da biomassa florestal nas características do solo da Amazônia. In: COSTA, J.M.M. Amazônia desenvolvimento ou retrocesso. Belém: CEJUP, 1992. 351p. (Coleção Amazoniana, 2).

FALESI, I.C.; BAENA, A.R.C. Mogno-africano (Khaya ivorensis A. Chev.) em sistema silvipastoril com leguminosa e revestimento natural do solo. Belém: Embrapa Amazônia Oriental, 1999. 52p. (Documentos, 4).

FALESI, I.C. et al. Análise econômica da produção do nim indiano no Estado do Pará. Belém: Embrapa Amazônia Oriental, 2000. 4p. (Comunicado Técnico, 43).

FALESI, I.C.; GALEÃO, R.R. Recuperação de áreas antropizadas da mesorregião do nordeste paraense através de sistemas agroflorestais. Belém: Emater, 2002. 25p. (Documentos 1).

FEARNSIDE, P.M; BARBOSA, R.I. Soil carbon changes from conversion of forest to pasture in Brazilian Amazonia. Forest Ecology and Management, Amsterdã, 108, p.147-66, 1998.

GARCIA, R.; ANDRADE, C.M.S. Sistemas silvipastoris na região Sudeste. In: CARVALHO, M.M. et al. Sistemas agroflorestais pecuários: opções de sustentabilidade para áreas tropicais e subtropicais. Juiz de Fora: Embrapa-CNPGL; FAO, 2001. p.173-187.

HECHT, S.B. et al. The economics of cattle ranching in eastern Amazonia. Interciencia, Venezuela, v.13, n.5, p.233-240, 1988.

KOUL, O. et al. Properties and uses of neem, Azadirachta indica. Canadian Journal of Botany, Canadá, v.68, n.1, p.1-11, 1990.

LOURENÇO JÚNIOR, J.B. Variáveis produtivas, fisiológicas e de comportamento de zebuínos e bubalinos e fatores do ambiente físico em pastagem cultivada da ilha de Marajó. 1998. 127f. Tese (Doutorado em Ciências Biológicas) - Curso de Pós-graduação em Ciências Biológicas, Universidade Federal do Pará.

LOURENÇO JÚNIOR, J.B. et al. Alternative systems for feeding buffaloes in Amazon Region. In: BUFFALO SYMPOSIUM OF THE AMERICAS, 2002, Belém, PA. Proceedings... Belém:Embrapa, 2002. p.31-42. 
LOURENÇO JÚNIOR, J.B. et al. Sistema silvipastoril e pastejo rotacionado intensivo na produção leiteira de búfalas na pequena propriedade da Amazônia Oriental. In: CONGRESO LATINO AMERICANO DE AGROFORESTERIA PARA LA PRODUCCIÓN PECUARIA SOSTENIBLE, 4; SIMPOSIO SOBRE SISTEMAS SILVOPASTORILES PARA LA PRODUCCIÓN GANADERA SOSTENIBLE, 3., 2006, Varadero, Cuba. Anales... Varadero: EEPF “Indio Hatuey”/ ICA/IGAT/IIF, 2006. p.16-22.

LOURENÇO JÚNIOR, J.B.; GARCIA, A.R. Produção animal no Bioma Amazônico: atualidades e perspectivas. Revista Brasileira de Zootecnia, Viçosa, v.35, p.63-83, 2006.

MAGAlHÃES, J.A. et al. Tolerância de bovídeos a temperatura e umidade do trópico úmido. Porto Velho: EMBRAPA-CPAF Rondônia, 1998. 4p. (Comunicado Técnico, 147).

MARQUES, J.R.F.; CARDOSO, L.S. A bubalinocultura no Brasil e no mundo. In: OLIVEIRA, G.J.C. et al. O búfalo no Brasil. Cruz das Almas: UFBA, 1997. p.7-42.

MATOS, L.B. et al. Conforto térmico e taxas de concepção em búfalas criadas na Amazônia Oriental. In: CONGRESSO BRASILEIRO DE REPRODUÇÃO ANIMAL, 17., 2007, Curitiba, PR. Anais... Belo Horizonte, MG: CBRA, 2007.

MONTAGNINI, F. Sistemas agroflorestales: principios y aplicaciones en los tropicos. 2ed. San Jose: Organización para Estudios Tropicales, 1992. 622p.

MOTT, G.O. Measuring forage quantity and quality in grazing trials. In: SOUTERN PASTURE AND FORAGE CROP IMPROVEMENT CONFERENCE, 37., 1980, Nashville, Tenesse. Proceedings... Nashvilhe, 1980. p.3-9.

NASCIMENTO, C.N.B; MOURA CARVALHO, L.O.D. Criação de búfalos: alimentação, manejo, melhoramento e instalações. Brasília: EMBRAPA-SPI, 1993. 403p.

NEVES, B.P.; NOGUEIRA, J.C.M. Cultivo e utilização do nim indiano (Azadirachta indica A. Juss.). Goiânia: EMBRAPA/CNPAF, 1996. 32p.

PAYNE, W.J.A. A review of the possibilities for integrating cattle and tree crop production systems in the tropics. Forest Ecology and Management, Amsterdã, v.12, p.136, 1985.

PARANHOS DA COSTA, M.J.R. Ambiência na produção de bubalinos destinados ao abate. In: ENCONTRO ANUAL DE
ETOLOGIA, 2000, Florianópolis, SC. Anais... Florianópolis: Sociedade Brasileira de Etologia, 2000. V.18, p.26-42.

PEIXOTO, A.M. et al. Volumosos para bovinos. Piracicaba: FEALQ, 1993. p.148.

PEZO, D.; IBRAHIM, M. Sistemas silvipastoriles. Costa Rica: CATIE, Proyecto Agroflorestal CATIE/GTZ, 1998. 12p. (Materialies de Enseñanza/CATIE, 40).

SERRÃO, E.A.S.; HOMMA, A.K.O. Agriculture in the Amazon: the question of sustainability. Washington: Committee for Agriculture and Environment in the Humid Tropics, 1991. 100p.

SHALASH, M.R. Environmental effects on water buffalo production. World Animal Review, Roma, v.77, n.4, p.2125, 1994.

TEREZO, E.F.M. Reflorestamento no Brasil e no Estado do Pará. In: WORKSHOP SOBRE REFLORESTAMENTO, 2002, Belém, PA. Anais... Belém: AIMEX, 2002. p.38-47.

TITTO, E.A.L. et al. Efeito do banho de água sobre o conforto térmico de bubalinos. In: CONGRESSO DE ZOOTECNIA, 6., 1997, Lisboa. Actas. Lisboa: APEZ, 1997. V.1, p.15-18.

TOWNSEND, C.R. et al. Condições térmicas ambientais sob diferentes sistemas silvipastoris em Presidente Médici - Rondônia. Rondônia: EMBRAPA-CPAF Rondônia, 2000. 4p. (Comunicado Técnico, 188).

VEIGA, J.B.; SERRÃO, J.A. Sistemas silvipastoris e produção animal: a experiência da Amazônia brasileira. In: SOCIEDADE BRASILEIRA DE ZOOTECNIA/PASTAGENS, 27., 1990, Campinas, SP. Anais... Piracicaba: FEALQ, 1990. p.37-68.

VEIGA, J.B. et al. A pecuária na fronteira agrícola da Amazônia: O caso do município de Uruará, PA, região da Transamazônica. Belém: Embrapa-CPATU, 1996. 61p. (Documentos, 87).

VEIGA, J.B.; PEREIRA, C.A. Novas alternativas arbóreas para sistemas silvipastoris na Amazônia Oriental. In: CONGRESSO BRASILEIRO EM SISTEMAS AGROFLORESTAIS, 2., 1998, Belém, PA. Anais.. Belém: Embrapa-CPATU, 1998. p.22830 .

VILELA, D.; ALVIM. J.M. Produção de leite em pastagem de Cynodon dactylon, (L) Pers, cv. Coast-Cross. In: WORKSHOP SOBRE O POTENCIAL FORRAGEIRO DO GÊNERO CYNODON, 1996, Juiz de Fora, MG. Anais... Juiz de Fora: EMBRAPA - CNPGL, 1996. p.77-91. 